\title{
Preparation of atropia by means of chloroform
}

\section{Rabourdin}

To cite this article: M. Rabourdin (1850) Preparation of atropia by means of chloroform, Philosophical Magazine Series 3, 37:253, 542-543, DOI: 10.1080/14786445008646675

To link to this article: http://dx.doi.org/10.1080/14786445008646675

册 Published online: 30 Apr 2009.

Submit your article to this journal $2 \pi$

Џ Article views: 2

Q View related articles $₫$ 
tion to generate water; and besides these compounds formed with oxygen, we have nitrogen to aid*, which is more incoercible than water or carbonic acid. Since at the heat produced by the combustion of hydrogen or carbon, with pure oxygen, iron, the most tenacious of all the materials at our command, is perfectly fusible, it is evident that by mechanism we cannot restrain the expansive force of the gaseous products producible as above represented. I believe I may say, that water has never been confined under a white heat. Yet the expansive force of liquid carbonic acid is at the freezing-point of water 36 times as great as the pressure of this liquid at its boilingpoint. It has already been observed, that nitrogen in expansive violence must go beyond carbonic acid. It follows, that excepting the blow of a hammer, or the force created by gravitation in falling bodies, we have no means by which we can enable nitre, in the state of incandescent igneous fluidity, to come into close contact, even for an instant, with masses of combustible matter, like those which it was made to encounter in the store of Messrs. Crocker and Warren.

It is to be presumed that it has been the want of this force which has caused efforts to produce explosions between nitre and combustibles to fail; and it is to the presence of this force, where the fall of enormous masses of agglutinated combustible matter upon incandescent liquefied nitre may be reiterated, that $I$ ascribe the destructive explosions, which, under such circumstances, have been so prolific of impoverishment, mutilation, and death.

\section{Intelligence and Miscellaneous Articles. PREPARATION OF aTROPIA BY MEANS OF ChLOROFORM. BY M. RABOURDIN.}

THE following is the process proposed by the author above named : -Take fresh belladonna as soon as it begins to flower; bruise it in a marble mortar and press out the juice, which is to be heated to $80^{\circ}$ or $90^{\circ}$ centigrade to coagulate the albumen. When the juice thus clarified is cold, add to every litre 4 grammes of caustic potash and 30 grammes of chloroform; shake the whole for a minute, and let it stand. In half an hour, the chloroform holding atropia is deposited, having the appearance of a greenish oil; the supernatant liquor is poured off, and replaced by a little water; this is afterwards poured off, and the washing is to be continued till the water comes away limpid. The chloroform solution is then to be put into a small tubulated retort, and distilled on a water-bath until all the chloroform has passed into the receiver. The residue in the retort is to be treated with a little water, acidified with sulphuric acid, which dissolves the atropia, and leaves a green resinoid matter; the filtered

* Nitric acid consists of 1 atom of nitrogen as well as 5 of oxygen. 
solution is colourless. To have the atropia pure, it is only requisite to pour into the acid solution a slight excess of solution of carbonate of potash, and to dissolve the precipitate in rectified alcohol. This solution yields, by spontaneous evaporation, fine groups of acicular crystals of atropia.

In the absence of the fresh plant, the officinal extract, which has been well prepared, may be substituted for it : $\mathbf{3 0}$ grammes of extract of belladonna, prepared from the purified juice of the plant, were dissolved in 100 grammes of distilled water; to the filtered solution were added 2 grammes of caustic potash and 15 grammes of chloro.. form. After agitating the mixture for a minute and setting it aside for half an hour, the chloroform containing atropia was deposited, the supernatant liquor was decanted and replaced by water, which was three times renewed; the chloroformic solution weighed 11 grammes, so that 4 grammes of chloroform were lost during the manipulation. This solution exposed to the air rapidly evaporated, leaving a crystalline greenish mass consisting almost entirely of atropia; this, treated with dilute sulphuric acid, and precipitated by carbonate of potash, gave a precipitate weighing 16 centigrammes. It was totally soluble in rectified alcohol, and yielded by spontaneous evaporation fine needles of atropia.

The author of this mode of operating with belladonna is of opinion that it is susceptible of generalization, and of application to many other substances containing organic alkalies; if it does not prove an cconomical method of preparing these products, it will serve, at any rate, in some cases, as a ready means of estimating the value of certain commercial products.

In a future communication the author proposes to give a process for estimating quickly and commercially the alkalies of cinchonas, by acting on very small quantities of them; and will also show that by means of chloroform, traces of iodine may be ascertained more advantageously than by starch.-Comptes Rendus, Octobre 14, 1850.

ON THE COMPOSITION OF CERTAIN NATURAL ORGANIC BASES. BY M. A. DE PLANTA.

It is remarked by the author, that the researches of a great number of chernists have of late years given great impulse to the study of the composition of the vegetable alkalies. In this so cultivated a field there remain, however, some gaps to be filled, and this M. de Planta has, therefore, endeavoured to effect with respect to atropia, daturina and aconitina.

Atropia.-This was prepared by M. Merck of Darmstadt; it had the form of very fine needles, which were unalterable by exposure to the air, and heavier than water. At common temperatures, 1 part of atropia requires about 300 parts of water for solution. Alcohol dissolves it in all proportions; æther less readily.

At $90^{\circ}$ centigrade, atropia melts into a colourless transparent liquid, and becomes on cooling a brittle mass, in which, after longcontinued fusion, crystals are often observable grouped in stars. At $140^{\circ}$ it is partly volatilized, but the greater portion is decomposed. Heated on a strip of platina, it readily fuses, melts, swells up and 